THE MUSEUMS ASSOCIATION.

Swansea Conference, July, igi4.

THE Museums Association fittingly celebrated the completion of a quarter of a century's existence by an incursion into a hitherto unvisited countrythe Principality of Wales-Swansea being chosen as the meeting place.

The attendance was very large, and the papers and discussions reached a high standard of excellence. Particularly noteworthy were those dealing in a practical way with the preservation and restoration of works of art-a subject which has never previously received so much attention at an annual conference.

Representatives were sent by forty provincial museums and art galleries, five national museums (the British Museum, the British Museum of Natural History, the Victoria and Albert Museum, the National Museum of Wales, and the Museum of the Royal Botanic Gardens at Kew), and the London County Council.

The presidential chair was occupied by $\mathrm{Mr}$. Charles Madeley, Director of the Warrington Municipal Museum.

In his presidential address $\mathrm{Mr}$. Madeley invited the conference to consider "What is the true theory of a municipal museum?" To the community which desires to establish or to re-organise a museum, this is a vital question, and the president dealt with it in a manner at once comprehensive and illuminating. Municipal museums are mercifully free from any kind of departmental reguiations restricting their scope and activities, but this blessing has in the past been a somewhat mixed one, and one of the great functions of The Museums Association is to see that it is henceforth properly appreciated.

The president suggested that a museum might be defined as "a collection of specimens arranged with a purpose," and objected to that purpose being defined as "educational," by reason of the unattractive nature of the word and the unnecessary limitations imposed by it. This objection was the source of some misunderstanding on the part of those hearers who did not grasp the true significance of Mr. Madeley's remarks, although he made it abundantly clear that a museum must, in his view, be educational. The contents of the ideal museum should, according to the president, constitute a miniature or synopsis of the universe--the true microcosm, in fact-but with the great and essential difference that, in the museum, things are classified, and therefore intelligible, whilst in the world outside they are not. He quoted with approval the statement of Dr. Brown Goode that a museum should be "an institution for the preservation of those objects which best illustrate the phenomena of nature and the works of man, and the utilisation of these for the increase of knowledge and for the culture and enlightenment of the people."

The text being thus provided, there arises the necessity for a full and sound classification of the whole of the possible contents of such a museum.

Classifications, which might be thought suitable by some, have been prepared for the use of librarians, but the president pointed out that these are too arbitrary. In a library, where classification exists merely to promote ease of reference, this does not matter, but an orderly and logical conspectus is absolutely necessary when one of the great properties of the institution is "visualisation," as in the case of museums.

A filling-out of the broad scheme, drawn up by Brown Goode, is the kind of thing required. In it different points of view would be provided for, and the president called attention to one which has long suffered under an unjust stigma-namely, the economic point of view. "We may hope," said he, "that technology, and eventually even commerce, may meet with adequate recognition in the museum."

Mr. W. Grant Murray, Director of Art in Swansea, then gave an interesting account of the rise of the school of art and crafts and of the two local art galleries.

Dr. H. Langton related some of his experie1:ces in the preparation of the skulls of birds by means of the sand-process. His remarks brought forth a champion of the old water-maceration method, in the person of Mr. A. W. Gunn, of Newport, and it seemed fairly obvious from the discussion that, as in most matters, there is no one universally applicable method.

Mr. B. H. Mullen gave an account of the "Children's room" at the Salford Museum, which has been established with the intention of providing a series of introductions to the various major collections, and to bring young people into intelligent and sympathetic touch with them.

The Bankfield Museum publications were the subject of a note by the curator, Mr. H. Ling Roth.

On the evening of Tuesday, July 7, Mr. E. Rimbault Dibdin, curator of the Waiker Art Gallery, Liverpool, delivered a public lecture on "Wales and the Fine Arts, Past, Present, and Future."

Mr. E. Howarth opened a discussion on the subject of "The Museum and the Schools," in which he emphasised the great desirability of these rapidly developing institutions keeping in close touch. There should be greater collaboration between the curator and the teacher in order that the curator's work may be of a nature to deserve and receive a full measure of use and appreciation by members of the scholastic profession and their charges. Mr. Howarth alluded to the importance of the kinematograph as a force in school teaching, and, as it is scarcely possible to have a kinematograph in every school, he suggested that every municipal museum might usefully instal an instrument to exhibit films germane to the work of the institution.

A demonstration of the characteristics-colour, translucency, etc. - of the various types of porcelain formerly made in Swansea and neighbourhood was given by $\mathrm{Mr}$. Herbert Eccles.

Mr. Quick, under the title "The Protection and Restoration of Pictures," gave a number of hints on the care and treatment of paintings, drawings, and engravings.

Mr. Williams's paper on "The Renovation and Restoration of Oil-paintings, with Practical Experiments," was illustrated by some examples of "before and after" treatment.

Dr. H. S. Harrison, of the Horniman Museum, in a paper entitled "Ethnographical Collections and their Arrangement," advised the adoption of what has been described as the "topical" mode of arrangement, and showed by means of well-chosen lantern slides how the evolution of processes, utensils, instruments, etc., might be advantageously illustrated.

Some points in the construction and fittings of the new King Edward VII. galleries at the British Museum were described by Mr. R. A. Smith.

The final paper was one in which there was every evidence of a serious premeditated intention to fit a museum building for the purpose of adequately and comfortably displaying the objects to be housed in it. We refer to the design for the new museum and art gallery at Belfast, which was lucidly described by Mr. Arthur Deane. Here the curator and architect have evidently been in close collaboration, and have produced a design original in several features and full of promise.

NO. 2337 , VOL. 937 
The entertainment and hospitality meted out to the Association by the Mayor and Corporation of Swansea and the leading citizens were of a most lavish and thoroughly enjoyable character, and the local arrangements were carried out by Mr. W. Grant Murray with a smoothness and precision which have never been surpassed.

The Association, at its business meeting, elected a distinguished worker on the art side-Mr. E. Rimbault Dibdin-to be president for $194^{-1} 5$.

\section{THE HARDENING OF STEEL.}

$A^{\mathrm{T}}$ the May meeting of the Iron and Steel A Institute two papers were read and discussed dealing with the theory of the hardening of steel; they gave rise to one of the most interesting discussions of the meeting. While it is, of course, obvious that the more "practical" members of the institute take no interest in these discussions, it must be borne in mind that the theories of to-day become the foundations of the practice of tomorrow, and that therefore the "practical" man cannot in the least afford to despise or ignore what he likes to dismiss as "mere theory."

The two papers on hardening presented to the institute both put forward fairly definite theories, and at first sight these differ entirely from one another and still more from the older purely "allotropic" theory of hardening. It was interesting to find, however, that during the discussion not a single advocate of the other older theory - that of the so-called "carbonists" - came forward. When the views put forward by Profs. Edwards and Carpenter and by Mr. McCance are carefully compared, however, it will be found that they do not really differ very vitally either from one another or from the older allotropic view. All three theories agree in supposing that when carbon steel is cooled rapidly an essentially unstable transition product is formed which is itself intrinsically hard. The allotropic theory called this intermediate hard product "beta iron," and identified it with the beta iron which has a limited range of stable existence in pure iron and in low-carbon steels; Messrs. Edwards and Carpenter and the writer now identify it with the "hard amorphous phase" of Beilby, while Mr. McCance invents a new word and calls it "interstrained" iron. The real difference of opinion seems to centre on the question how this intermediate substance comes into existence.

Profs. Edwards and Carpenter approach the subject from the point of view of an analogy between the hardening by quenching of steel and of alloys of copper containing from ro to 13 per cent. of aluminium. These latter are somewhat hardened by quenching, and there is a corresponding similarity, on broad lines, between the respective constitutional diagrams; by quenching, both kinds of alloys are caused to pass rapidly through a transformation range. The resulting micro-structures also show a certain similarity, the aluminium-copper alloys exhibiting an acicular structure having some resemblance to the coarser kinds of martensite seen in hardened steels. The authors then endeavour to show that the structures of both quenched aluminium-copper alloys and of quenched steel arise from an identical cause, viz., highly multiplied twinning, which they believe to occur during quenching as a result of the internal strains caused during rapid cooling. The evidence that the martensite of steel is really equivalent to highly twinned austenite is, however, very weak, and it has yet to be proved or even shown to be likely that quenching can produce multiple twinning. In the discussion of this paper, the writer pointed out that to produce notable strain-hardening of a plastic metal by deformation needed the application of really large deformations, while, on the contrary, the amount of deformation (strain in contradistinction to internal stress) which could be caused in steel by quenching must be very small. It is further a very open question whether strain really ever produces direct twinning in a metal. Finally, it has yet to be shown that a twinned constituent is really materially harder than in the untwinned condition; the softness and ductility of such materials as rolled and annealed copper or brass, which are one mass of twinned crystals, points in the opposite direction. The idea put forward by Edwards and Carpenter that amorphous layers are formed on the twin boundaries in the process of twinning was well refuted by $\mathrm{Mr}$. Humfrey in the discussion, as he showed by means of models that twinning could and did occur without disarrangement of the space-lattice at the boundary. As a result of the whole discussion it appeared that the authors had attached altogether too much weight to the process of twinning, but that the formation of amorphous metal during the quenching process might well be looked upon as the real cause of hardeninga view which the late $F$. Osmond had put forward quite clearly a year or so before his death.

Mr. McCance's paper began a thoughtful consideration of the whole subject by a review of existing theories. Both in regard to the existence or otherwise of beta iron as an independent allotropic modification, and in regard to the amorphous theory, however, the author made the mistake of considering that the objections which he raised can settle the point and dispose of these theories in half a dozen words. The question as to the extent and nature of the differences between alpha and beta iron is still being closely discussed, and even if Weiss's magneton theory finds ultimate acceptance, it is still a question whether the magnetic transformations do not really constitute one type of allotropy, nor is it yet certain that they may not be associated with far-reaching changes in other properties. Again, as regards the amorphous theory, Mr. McCance's objections are based on a simple misunderstanding, coupled with an assumption, based on the magneton theory, which has yet to be justified. This assumption amounts to the view that only crystalline solids can be ferro-magnetic, and that consequently amorphous iron would necessarily be non-magnetic. Facts are, however, against this view, for colloidal suspensions of iron are strongly ferro-magnetic, and so are a number of oxides and salts of iron, some of the latter even in a state of solution.

Of much greater value are Mi. McCance's experimental studies of hardening in carbon steel, which lead him, finally, to put forward a theory of the hardening of steel by "interstrain," which is practically a translation of Osmond's view ascribing the hardness of quenched steel to the presence in it of "le fe:" alpha écroui.' It is only Mr. McCance's account of the nature of "interstrained" iron which it is difficult to accept. Declining to accept the views of Beilby and of Rosenhain as to the hardening of strained metals by the formation of layers of the amorphous phase, the author uses the word "interstrain" to denote a condition in which the regular crystalline arrangement is broken up generally, leaving a mass of irregularly arranged crystal fragments. It may well be asked what it is that holds these irregular and ill-fitting fragments together, and why an aggregate of such fragments should be harder than the aggregate of the larger pieces of crystal which constitute the ordinary soft metal? But beyond this

NO. 2337, VOL. 93] 